\title{
Impact of the 2013 French Pill Crisis on Women's Behaviour Regarding Contraception
}

\author{
Magali Lemaitre $\cdot$ Glenn Lastennet $\cdot$ \\ David Syr · Joseph Emmerich · Mahmoud Zureik
}

Published online: 6 February 2015

(C) The Author(s) 2015. This article is published with open access at Springerlink.com

\begin{abstract}
Context In the last decade, several epidemiological studies have shown the increased risk of venous thromboembolism associated with third- and fourth-generation oral contraceptives (C3Gs and $\mathrm{C} 4 \mathrm{Gs}$ ) versus older combined first- and second-generation oral contraceptives (C1Gs and C2Gs). In France, in December 2012, a lawsuit filed against the National Agency for the Safety of Medicines and Health Products (ANSM) by a patient who had experienced a stroke, possibly due to the use of a C3G, triggered a national 'pill crisis'. Consequently, a 'crisis cell' was set up and pre-existing health recommendations were reinforced. The main aim of this study was to evaluate, in real time, the impact of the French health authorities' recommendations and communications on French women's behaviour regarding contraception.

Methods Real-time monthly sales data reported during 2013 were compared with monthly sales data reported in 2012. Analyses were stratified according to the type of contraceptive and age. An index corresponding to the number of months of contraception sold was developed to facilitate comparison of the different contraceptives despite their distinct features and to assess the overall trend of contraception.
\end{abstract}

\footnotetext{
M. Lemaitre $(\bowtie) \cdot$ G. Lastennet · J. Emmerich · M. Zureik National Agency for the Safety of Medicines and Health Products (ANSM), 143-147 Boulevard Anatole France, 93285 Saint-Denis Cedex, France

e-mail: magali.lemaitre@ansm.sante.fr

D. Syr

Celtipharm, Vannes, France
}

Results After a 2-year analysis (2013 versus 2012), a significant $45 \%$ decrease $(p<0.0001)$ in C3G-4G sales was observed, compared with a significant increase of $30 \%(p<0.0001)$ in $\mathrm{C} 1 \mathrm{G}-2 \mathrm{G}$ sales. The sharp increase in $\mathrm{C} 1 \mathrm{G}-2 \mathrm{G}$ sales focused specifically on $\mathrm{C} 2 \mathrm{Gs}$ with an oestrogen concentration below $20 \mu \mathrm{g}$. Moreover, a large $(47 \%)$ increase was reported in sales of intrauterine devices $(p<0.0001)$. Finally, taking all types of contraceptive sales into account, a slight decrease $(1 \%)$ in overall sales was identified.

Conclusion Thanks to an effective national communication plan, real-time monitoring of drug sales and favourable reactions from physicians and patients, French women changed their behaviour regarding contraception. However, this study was conducted over a short period following the crisis. A longitudinal analysis is required in order to assess any real long-term changes.

\section{Introduction}

The thromboembolic risk of combined oral contraceptives (COCs) has been suspected ever since the market launch of these medicinal products in the 1960s [1, 2]. In the 1990s, several studies highlighted an additional risk of venous thromboembolism (VTE) associated with COCs containing gestodene and desogestrel (so-called third-generation pills [C3Gs]) compared with older products containing levonorgestrel (second-generation pills [C2Gs]) [3-5]. These results led to the first 'pill crisis', which mostly affected the UK. Women suddenly stopped taking their COC treatment in response to this crisis. A few months later, abortion rates in the UK rose by up to $10 \%$ [6]. This crisis triggered the first European assessment of the VTE risk associated with C3Gs. In 1996, information regarding the VTE risk was 
included for the first time in the Summary of Product Characteristics of each COC.

A second European assessment of the VTE risk associated with $\mathrm{C} 3 \mathrm{Gs}$ was conducted by the European Medicines Agency (EMA) [7] in 2001, as epidemiological studies investigated and highlighted a 2-fold greater risk of VTE associated with C3Gs compared with C2Gs [3-5]. At the same time, the French health authorities carried out the first benefit/risk assessment concerning third-generation combined hormonal contraceptives (CHCs), including C3Gs, transdermal patches and vaginal rings. They concluded that, despite the continuing significant medical advantage, improvements in terms of medical benefits had not been clearly identified. With the introduction in subsequent years of hormonal contraceptives containing drospirenone (so-called fourth-generation products [C4Gs]), the thirdand fourth-generation $\mathrm{CHCs}$ were investigated by the French health authorities because of their inherent risk of VTE. The latest epidemiological studies have corroborated the results of earlier work focusing on VTE risks associated with C3Gs [8-12].

\section{Critical Trigger Factors}

The French pill crisis started in mid-December 2012 after a patient who had experienced a stroke, possibly due to the use of a C3G, filed a lawsuit against the National Agency for the Safety of Medicines and Health Products (ANSM). A few days later, the media exacerbated the crisis surrounding the VTE risks associated with CHCs. Following this event, a 'crisis cell' was set up by ANSM to manage this pill crisis. In order to boost the impact of previous measures set up to change women's behaviour regarding contraception, and consequently reduce the risk of VTE, an European reassessment of the benefit/risk ratio was conducted to restrict the indication for C3Gs and C4Gs to second-line therapy, in contrast to first- and second-generation pills (C1Gs and C2Gs) [13]. Simultaneously, the French health authorities took the following steps to strengthen their previous recommendations: issue of communications to healthcare professionals and the public regarding VTE-related risks [14]; strengthening of recommendations by the French health authorities [15, 16]; meetings with learned societies (the Gynaecological Association, Midwives' Association, etc.); and follow-up of $\mathrm{CHC}$ sales with monthly press conferences/media interviews. Furthermore, in March 2013, a study was developed to estimate the number of VTEs attributable to CHCs in France between 2000 and 2011 [17].

The main aims of this study were to analyse and assess post-crisis changes in French women's behaviour regarding contraception.

\section{Methods}

\section{Data Sources}

\section{Contraceptive Sales Data}

This study was conducted from a large follow-up of contraceptive sales data actively recorded in France since January 2012. Weekly contraceptive sales data were extracted from a stratified sample of 3,004 community pharmacies on the French mainland. The procedure was set up by Celtipharm [18]. The real-time sales data for these pharmacies have been automatically and continuously reported on a daily basis since 2007. An updated and exhaustive database of 22,143 active French community pharmacies provided a representative set of stratification data based on sales revenue (six levels for global revenue and four levels per type of sales: prescribed drugs, overthe-counter [OTC] drugs and other types of sales); location (five geographical areas); and sales area (five types, ranging from rural to densely urban). Each stratum had a minimum of 30 pharmacies or was merged with a neighbouring stratum. Sampling rates per stratum were computed with the Neyman optimal allocation algorithm [19]. Real-time extrapolations from this sample have already been used in previously published studies [20-22].

\section{Analyses}

\section{Types of Contraceptive}

In this study, all contraceptives except for condoms were taken into consideration: $\mathrm{CHCs}(\mathrm{C} 1 \mathrm{G}-4 \mathrm{Gs}$ and non-oral combined contraceptives [NOCCs], such as patches and vaginal rings); intrauterine devices (IUDs); levonorgestrelreleasing intrauterine systems (LNG-IUSs); contraceptive implants; and emergency contraception (the 'morning-after pill').

Condoms were excluded, as more than $90 \%$ of condoms are purchased in French supermarkets.

Different types of contraceptive can be identified according to the method of administration. In this study, we distinguished between two major types, summarized in Table 1 .

The first type corresponds to contraceptives used on a regular basis, characterized by a monthly or quarterly purchase. This category includes CHCs, divided into three groups: C1G-2Gs, C3G-4Gs and NOCCs, including patches and vaginal rings.

The second category corresponds to contraceptives comprising 'one-time' administration, such as IUDs, LNGIUSs and implants. This category was divided into two groups: an IUD group and a one-time hormonal contraceptive (OTHC) group, including LNG-IUSs and implants. 
Table 1 Pharmaceutical forms of contraception

\begin{tabular}{lll}
\hline $\begin{array}{l}\text { Types of } \\
\text { contraception }\end{array}$ & $\begin{array}{l}\text { Use and pack characteristics: } \\
\text { regular (3 months or 1 month) } \\
\text { or one-time }\end{array}$ & $\begin{array}{l}\text { Details: type of hormone and } \\
\text { oestrogen concentration }\end{array}$ \\
\hline COCs & & Progesterone/oestrogen $(20 \mu \mathrm{g}, 30-40 \mu \mathrm{g}, 50 \mu \mathrm{g})$ \\
C1G-2Gs & Regular & $\begin{array}{l}\text { Progesterone/oestrogen }(15-20 \mu \mathrm{g}, 30-40 \mu \mathrm{g}, \\
\text { natural oestrogens })\end{array}$ \\
C3G-4Gs & Regular & $\begin{array}{l}\text { Progesterone/oestrogen } \\
\text { NOCCs }\end{array}$ \\
Patches & Regular & Progesterone/oestrogen \\
Vaginal rings & Regular & - \\
IUDs & One-time & \\
OTHCs & & Progesterone \\
LNG-IUSs & One-time & Progesterone \\
Implants & One-time & \\
\hline
\end{tabular}

C1G-2Gs first- and secondgeneration oral contraceptives, $C 3 G-4 G s$ third- and fourthgeneration oral contraceptives, COCs combined oral contraceptives,

IUDs intrauterine devices, LNG-IUSs levonorgestrelreleasing intrauterine systems, NOCCs non-oral combined contraceptives, OTHCs onetime hormonal contraceptives

\section{Overall Trend}

Contraceptive sales data were studied over a 2-year period in order to investigate changes in women's behaviour regarding contraception.

More precisely, we compiled weekly contraceptive sales data, and the analysis was based on monthly sales data reported between January and December 2013 (postFrench pill crisis). This information was then compared with monthly sales data reported between January and December 2012 (pre-French pill crisis). The Wilcoxon signed rank test was used to compare monthly sales data and to study changes between 2012 and 2013 .

Moreover, an index was developed to facilitate comparison of the different contraceptives despite their distinct features (contraceptives requiring regular usage, contraceptives characterized by one-time administration, etc.). This index corresponds to the number of months of contraception sold over the study period. Two study periods, each of 1 year's duration, were considered-namely, 2012 and 2013. Consequently, a 3-month pack bought in January accounted for a contraceptive period of 3 months, a 3-month pack purchased in December accounted for 1 month in that year, and an IUD purchased in January accounted for 12 months of contraception. This index allowed us to study the overall trend including all contraceptives.

\section{Oestrogen Concentrations}

The oestrogen concentrations of oral contraceptives were analysed. The $\mathrm{C} 1 \mathrm{G}-2 \mathrm{G}$ group was divided into three categories: the first had an oestrogen concentration of $20 \mu \mathrm{g}$, the second had a concentration ranging from 30 to $40 \mu \mathrm{g}$; and the third had a concentration of $50 \mu \mathrm{g}$. The $\mathrm{C} 3 \mathrm{G}-4 \mathrm{G}$ group was divided into three categories: the first had a concentration of 15-20 $\mu \mathrm{g}$; the second had a concentration of $30-40 \mu \mathrm{g}$; and the third accounted for other oestrogens, called 'natural oestrogens'.

\section{Age Groups}

Age group analyses were conducted to assess the impact of the French health authorities' recommendations for young people - a population particularly exposed to COCs.

Four age groups were considered: 15- to 19-year-olds; 20- to 29-year-olds; 30- to 39-year-olds; and 40- to 49-year-olds.

Behaviour regarding contraception in women under 15 and over 50 years of age was not studied, since contraceptive sales in these age groups represented fewer than 0.3 and $2.5 \%$, respectively, of overall contraceptive sales data.

\section{Results}

Types of Contraceptive

\section{Combined Oral Contraceptive Group}

As observed in Table 2, a significant $30 \%$ increase estimated from the index, corresponding to an increase of $7,555,406$ months of contraception sold, was reported for C1G-2G sales in 2013, compared with sales reported in $2012(p<0.0001)$. Under the hypothesis of continuous use over the 12 months of a year, this increase would correspond to about 630,000 additional women using C1G-2Gs in 2013 compared with 2012.

As shown in Fig. 1, a maximum increase of $37 \%$ was reported in November 2013 compared with November 2012. 
Table 2 Global changes in contraceptive sales data

\begin{tabular}{|c|c|c|c|c|}
\hline \multirow[t]{2}{*}{ Types of contraception } & \multicolumn{2}{|c|}{ Number of months of contraception sold } & \multirow{2}{*}{$\begin{array}{l}\text { Change: } 2013 \text { versus } 2012 \\
\text { (minimum; maximum) }\end{array}$} & \multirow[t]{2}{*}{$p$ value } \\
\hline & 2012 & 2013 & & \\
\hline \multicolumn{5}{|l|}{ COCs } \\
\hline $\mathrm{C} 1 \mathrm{G}-2 \mathrm{Gs}$ & $25,204,629$ & $32,760,035$ & $+30 \%(+18 ;+37)$ & $<0.0001$ \\
\hline $\mathrm{C} 3 \mathrm{G}-4 \mathrm{Gs}$ & $22,211,840$ & $12,219,726$ & $-45 \%(-25 ;-54)$ & $<0.0001$ \\
\hline \multicolumn{5}{|l|}{ NOCCs } \\
\hline Patches & 346,238 & 291,488 & $-16 \%(-24 ;-9.7)$ & 0.0010 \\
\hline Vaginal rings & 909,493 & 799,816 & $-12 \%(-16 ;-5.6)$ & 0.0010 \\
\hline IUDs & $1,960,361$ & $2,878,963$ & $+47 \%(+16 ;+69)$ & $<0.0001$ \\
\hline \multicolumn{5}{|l|}{ OTHCs } \\
\hline LNG-IUSs & $2,470,427$ & $2,322,014$ & $+15 \%(+3.4 ;+30)$ & $<0.0001$ \\
\hline Implants & $1,363,599$ & $1,676,418$ & $+23 \%(+1.4 ;+44)$ & $<0.0001$ \\
\hline
\end{tabular}

C1G-2Gs first- and second-generation oral contraceptives, C3G-4Gs third- and fourth-generation oral contraceptives, COCs combined oral contraceptives, IUDs intrauterine devices, LNG-IUSs levonorgestrel-releasing intrauterine systems, NOCCs non-oral combined contraceptives, OTHCs one-time hormonal contraceptives

Fig. 1 Monthly sales data for first- and second-generation oral contraceptives (C1G-2Gs) and third- and fourth-generation oral contraceptives (C3G-4Gs) in France from January to December 2013, versus January to December 2012

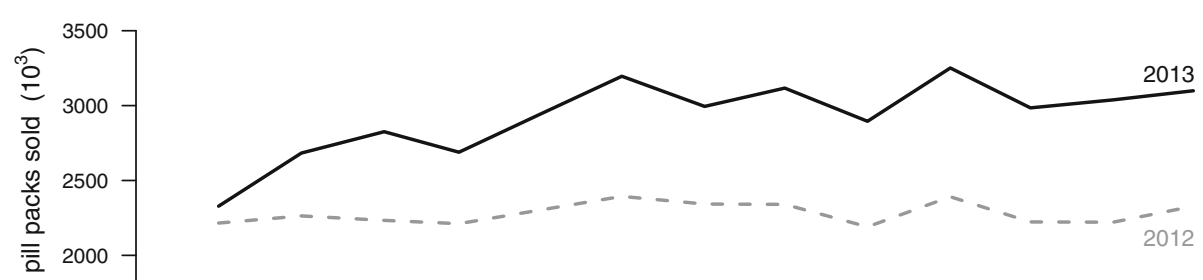

C1G-2G group

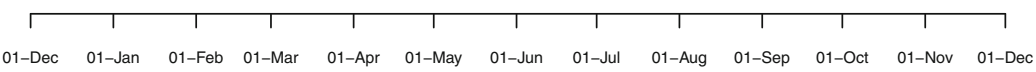

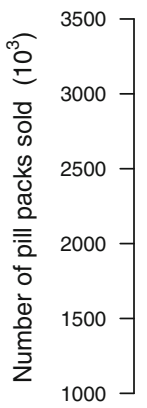

C3G-4G group

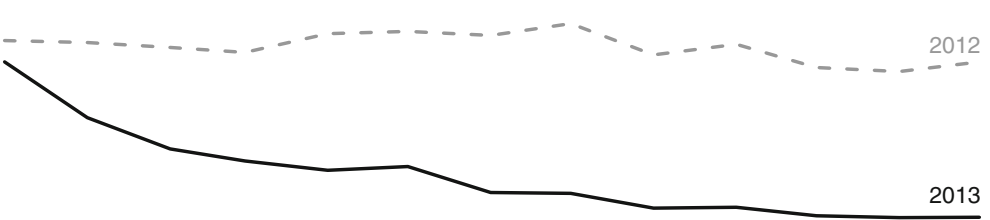

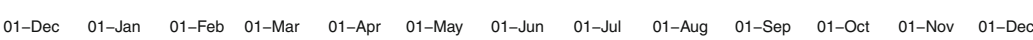

Regardless of age group, the index showed that $\mathrm{C} 1 \mathrm{G}-2 \mathrm{G}$ sales increased in 2013 compared with 2012, with significant increases of 45, 36, 24 and $16 \%$ in the 15- to 19-year, 20- to 29-year, 30- to 39-year and 40- to 49-year age groups, respectively $(p<0.0001)$. Monthly changes by age group are illustrated in Fig. 2. Consequently, the age distribution for C1G-2G sales changed because of this overall rise $(p<0.0001)$. The majority of $\mathrm{C} 1 \mathrm{G}-2 \mathrm{G}$ sales were reported in the 20- to 29-year age group, accounting for approximately $45 \%$ of sales, followed by 30 - to 39 -year-olds, with around $25 \%$ of sales, and the 15- to 19-year and 40- to 49-year age groups each representing around $14 \%$ of sales.

Meanwhile, the sales of $\mathrm{C} 3 \mathrm{G}-4 \mathrm{Gs}$ decreased sharply (45\%), with 9,992,114 fewer months of contraception sold in 2013 compared with $2012(p<0.0001)$ (Table 2), and may have corresponded to 833,000 women stopping use of 
Fig. 2 Distribution of monthly sales of first- and secondgeneration oral contraceptives (C1G-2Gs) and third- and fourth-generation oral contraceptives (C3G-4Gs), classified by age group, in France in 2012 and 2013. The bottom and top of each box are the first and third quartiles, respectively, and the horizontal band inside the box is the median. The ends of the whiskers represent remote values of up to 1.5 times the interquartile range
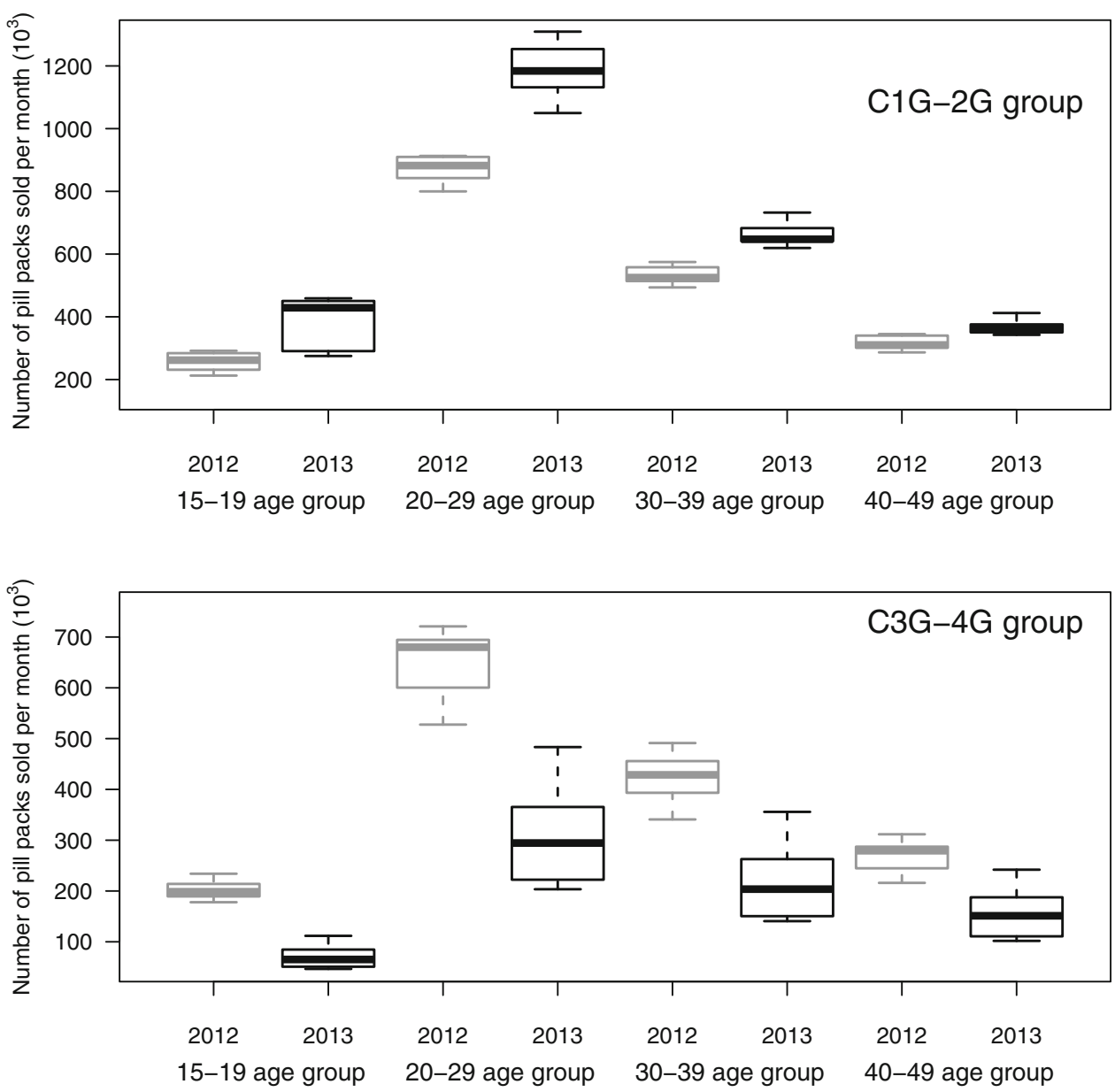

C3G-4Gs in 2013. A decline of $54.5 \%$ was reported in December 2013 compared with December 2012 (Fig. 1).

In 2013, a decrease in C3G-4G sales was observed in all age groups, compared with the previous year's sales, with decreases of $65,53,48$ and $41 \%$ in the 15- to 19-year, 20to 29-year, 30- to 39-year and 40- to 49-year age groups, respectively ( $p<0.0001$ ) (Fig. 2).

The age distribution of sales changed between 2012 and 2013 ( $p<0.0001$ ). In December 2013, this age distribution pattern was characterized by a majority of products being purchased by 20- to 29-year-olds (42\%), followed by 30 - to 39-year-olds (28\%), 40- to 49-year-olds (20\%) and 15 - to 19 -year-olds (9\%).

\section{Oestrogen Concentrations}

Taking the oestrogen concentration into account, the changes were mainly evident in $20 \mu \mathrm{g}$ C1G-2G sales in 2013, which were 2.1 times greater than those reported in 2012 (Fig. 3; Table 3), corresponding to a sales increase of $6,448,769$ packs of $20 \mu \mathrm{g} \mathrm{C1G-2G}$ pills.

Conversely, sales data showed that 15-20 $\mu \mathrm{g} \mathrm{C} 3 \mathrm{G}-4 \mathrm{G}$ and 30-40 $\mu \mathrm{g} \mathrm{C3G-4G} \mathrm{sales} \mathrm{were} 1.9$ times lower in 2013 than in 2012 (Table 3).
Consequently, $20 \mu \mathrm{g} \quad \mathrm{C} 1 \mathrm{G}-2 \mathrm{G}$ sales represented $25.6 \%$ of COC sales in 2013, compared with $11.7 \%$ in 2012. Conversely, the proportions of $15-20 \mu \mathrm{g}$ C3G-4G and 30-40 $\mu \mathrm{g}$ C3G-4G sales decreased, accounting for 28 and $15.8 \%$ of COC sales, respectively, in 2012, compared with 15.4 and $8.5 \%$, respectively, in 2013.

A small difference in sales was reported for $30-40 \mu \mathrm{g}$ C1G-2Gs; this group represented $47 \%$ of COC sales in 2013 and $41 \%$ in 2012. No difference was observed for $50 \mu \mathrm{g} \mathrm{C1G-2Gs} \mathrm{and} \mathrm{for} \mathrm{natural} \mathrm{oestrogen} \mathrm{C3G-4Gs,}$ which accounted for 5.0 and $2.9 \%$ of COC sales, respectively, during the 2 years.

The December 2013 sales data confirmed changes in women's behaviour following the French pill crisis. More precisely, the proportion of $\mathrm{C} 1 \mathrm{G}-2 \mathrm{G}$ sales versus C3G-4G sales was 78/22\% in December 2013, compared with 55/45\% in December 2012 and $52 / 48 \%$ in December 2011. Taking all generations of COCs into account, we estimated a global decrease in COC sales of $5.1 \%$ in 2013 compared with those reported in 2012, corresponding to 2,436,708 fewer months of contraception sold, involving about 200,000 women. 
Fig. 3 Annual sales of firstand second-generation oral contraceptives (C1G-2Gs) and third- and fourth-generation oral contraceptives (C3G-4Gs), classified by oestrogen concentration, in France in 2012 and 2013

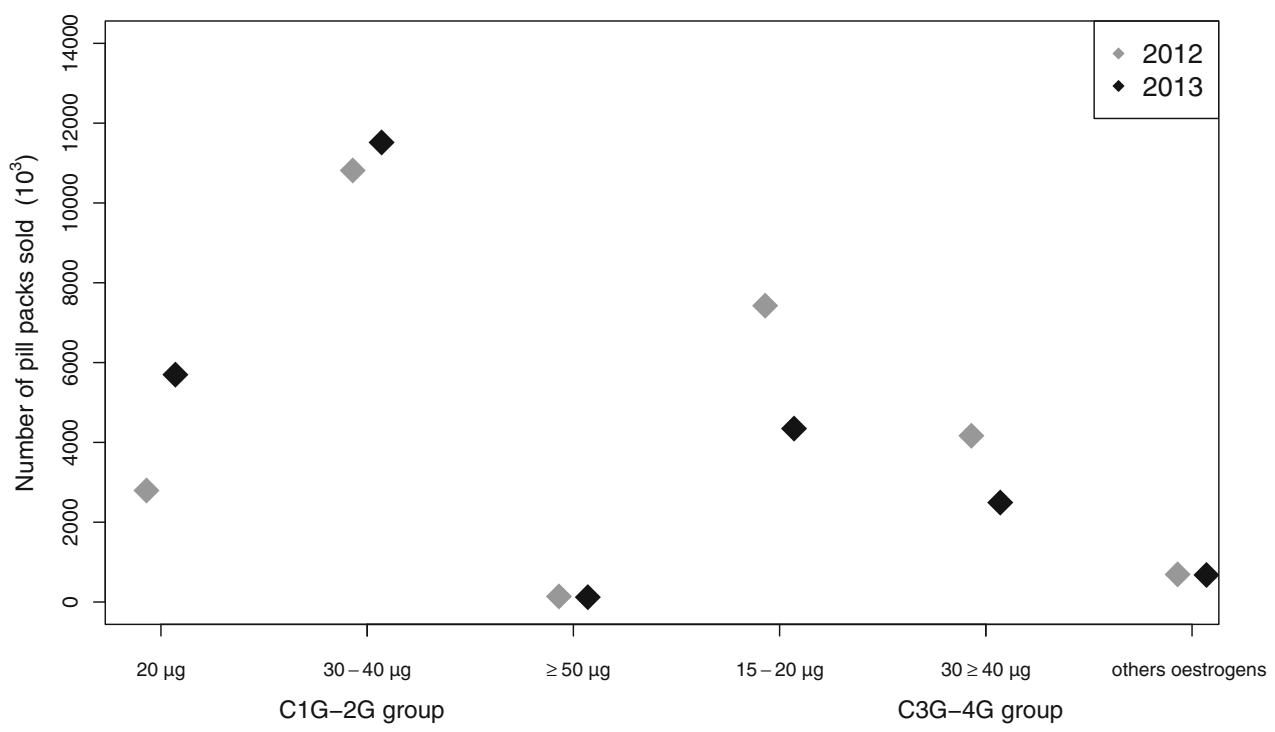

Table 3 Distribution of combined oral contraceptive (COC) sales, by generation and oestrogen concentration

\begin{tabular}{|c|c|c|c|c|c|c|}
\hline \multirow[t]{2}{*}{ Types of COC } & \multicolumn{2}{|c|}{ Number of pill packs sold } & \multicolumn{2}{|c|}{ Global distribution (\%) } & \multicolumn{2}{|c|}{ Distribution by generation (\%) } \\
\hline & 2012 & 2013 & 2012 & 2013 & 2012 & 2013 \\
\hline \multicolumn{7}{|l|}{$\mathrm{C} 1 \mathrm{G}-2 \mathrm{Gs}$} \\
\hline $20 \mu \mathrm{g}$ & $6,019,912$ & $12,468,680$ & 11.7 & 25.6 & 21.9 & 34.9 \\
\hline $30-40 \mu \mathrm{g}$ & $21,155,789$ & $23,013,627$ & 41.1 & 47.2 & 77.1 & 64.4 \\
\hline $50 \mu \mathrm{g}$ & 268,417 & 238,395 & 0.5 & 0.5 & 1.0 & 0.7 \\
\hline \multicolumn{7}{|l|}{ C3G-4Gs } \\
\hline $15-20 \mu \mathrm{g}$ & $14,391,109$ & $7,480,846$ & 28.0 & 15.4 & 59.8 & 57.5 \\
\hline $30-40 \mu \mathrm{g}$ & $8,135,890$ & $4,140,929$ & 15.8 & 8.5 & 33.9 & 31.8 \\
\hline Natural oestrogens & $1,502,194$ & $1,390,993$ & 2.9 & 2.9 & 6.3 & 10.7 \\
\hline
\end{tabular}

$C 1 G-2 G s$ first- and second-generation oral contraceptives, $C 3 G-4 G s$ third- and fourth-generation oral contraceptives

\section{Non-Oral Combined Contraceptive Group}

In 2013, sales of NOCCs (patches and vaginal rings) decreased overall by 164,426 months of contraception sold $(-13 \%)$, compared with the 2012 figures $(p=0.001)$. This result could have involved approximately 14,000 women.

\section{One-Time Hormonal Contraceptive Group}

A moderate increase of $18 \%$, or 674,407 more months of contraception sold, was observed in the sales of OTHCs, including LNG-IUSs and implants, in 2013 compared with 2012 ( $p<0.0001)$ (Fig. 4; Table 2). More precisely, about 89,000 women resorted to use of an OTHC in 2012. The rise was reported in all age groups, amounting to $28 \%$ in the 15 - to 19 -year age group, $19 \%$ in the 20 - to 29 -year age group, $15 \%$ in the 40- to 49-year age group and $13 \%$ in the 30- to 39-year age group $(p<0.0001)$. The age distribution of OTHC sales reported in December 2013 was as follows: $40 \%$ in the 30- to 39-year age group, $29 \%$ in the 40 - to 49 -year age group, $26 \%$ in the 20 - to 29 -year age group and $5 \%$ in the 15 - to 19 -year age group.

\section{Intrauterine Device Group}

In 2013, the greatest relative increase in sales out of all contraceptive groups was observed in the IUD group, with a rise of $47 \%(p<0.0001)$ (Table 2$)$ compared with IUD sales in 2012, corresponding to a difference of 918,602 more months of contraception sold and involving about 125,000 women. The increases ranged from $24 \%$ (in October 2013 versus October 2012) to $69 \%$ (in February 2013 versus February 2012). Women under 40 years of age were most affected by these increases. The reported increases were in excess of $60 \%$ among 20- to 29-year-olds and $50 \%$ among 30- to 39-year-olds $(p<0.0001)$, involving about 38,400 and 55,800 women, respectively. An increase of $22 \%$ was recorded among women aged 40 to 49 years. These results led to a change in the age 
Fig. 4 Monthly sales data for one-time hormonal contraceptives (OTHCs; including levonorgestrelreleasing intrauterine systems [LNG-IUSs] and contraceptive implants) and intrauterine devices (IUDs) in France from January to December 2013, versus January to December 2012
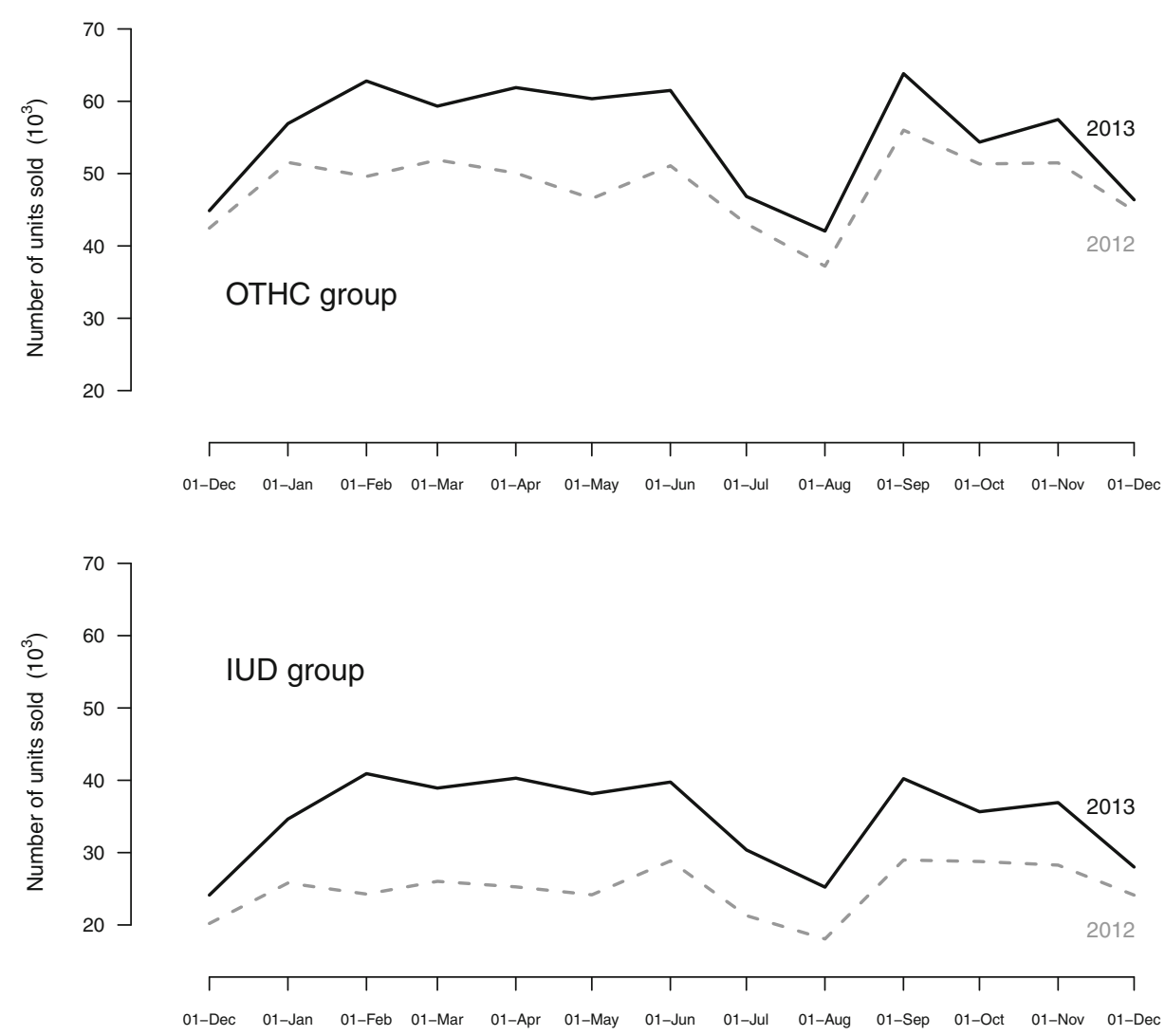

distribution pattern in 2013 compared with 2012 $(p<0.0001)$, with $48 \%$ of sales being recorded in the 30 - to 39 -year age group, $26 \%$ in the 20 - to 29 -year age group and $25 \%$ in the 40- to 49-year age group in 2013. In 2012 , this distribution pattern was $46 \%$ in the 30- to 39 -year age group, $30 \%$ in the 40 - to 49 -year age group and $23 \%$ in the 20 - to 29 -year age group. IUD sales recorded in the 15- to 19-year age group were 2.4 times greater in 2013 than in 2012. However IUD sales in this age group accounted for fewer than $1 \%$ of total IUD sales.

Finally, taking all types of contraceptive sales into consideration, a small overall decrease of 600,547 months of contraception sold ( $1 \%$ ) was reported in 2013 compared with 2012. Under the hypothesis of continuous use over the 12 months of a year, this result corresponded to a decrease of 50,000 women using contraception. Conversely, sales data for emergency contraception showed that a significant, albeit slight, rise of $4.4 \%$, involving about 66,138 women, was reported in 2013 compared with 2012.

\section{Discussion}

Despite previous warnings in 2004, when the French health authorities recommended use of $\mathrm{C} 3 \mathrm{G}-4 \mathrm{Gs}$ as second-line therapy only [15], and epidemiological studies highlighting the risk of VTE associated with COCs [10-12, 23], C3G4Gs were prescribed to the same extent as $\mathrm{C} 1 \mathrm{G}-2 \mathrm{Gs}$ prior to the mid-December 2012 French pill crisis. More precisely, $48 \%$ of COC sales were attributed to C3G-4Gs in 2011. This result confirmed that the warnings from the French health authorities regarding the VTE risk and recommendations for use of $\mathrm{C} 2 \mathrm{Gs}$ as first-line treatment were widely unknown or misunderstood. In order to manage the French pill crisis occurring in December 2012, a crisis cell was set up by the French health authorities and several health recommendations were reinforced.

The aim of this study was to evaluate the impact of the recommendations made by the French health authorities on the behaviour of French women regarding contraception. This is the first study to provide a systematic comparison of the use of contraceptives in France during the French pill crisis with data reported in 2012, based on a detailed comparison of age groups and types of contraceptive. The French pill crisis and health authority recommendations are believed to have resulted in a significant $45 \%$ decrease in sales of $\mathrm{C} 3 \mathrm{G}-4 \mathrm{Gs}$ and, conversely, a significant $30 \%$ increase in sales of C1G-2Gs, mainly concerning C1G-2Gs with a minimal oestrogen concentration $(20 \mu \mathrm{g})$. Under the hypothesis of continuous use over the 12 months of a year, 
these results would correspond to a decrease of 833,000 women using C3G-4Gs and conversely about 690,000 additional women using C1G-2Gs in 2013 compared with 2012. In 2012, 15- to 39-year-olds were mostly affected by behavioural changes regarding contraception. Moreover, the French pill crisis impacted upon IUD sales, which increased by $47 \%$ in 2013 compared with 2012. More precisely, nearly 125,000 additional women resorted to use of an OTHC in 2013 compared with 2012. Finally, taking all types of contraceptive sales into account, a small decrease $(1 \%)$ in overall sales, involving 50,000 women, was reported in 2013 compared with 2012. Conversely, an increase of $4.4 \%$ in sales of emergency contraception, involving about 66,138 women, was reported in 2013 compared with 2012.

There were several limitations in our study. First, contraceptive sales data in 2013 were compared with those reported in 2012. However, the French pill crisis started in mid-December 2012, and we cannot rule out the possibility that the change in the mentality of women towards contraception began in that month. However, changes reported in December 2012 probably led to an underestimation of the overall trend. In order to investigate this possibility, we carried out a sensitivity analysis using December 2011 sales data instead of December 2012 sales data. Similar results were recorded. More precisely, the decrease in C3G-4G sales in December 2013 compared with December 2012 was $54.5 \%$, versus a decrease of $57.6 \%$ between December 2013 and December 2011. Similarly, the proportions of sales of $\mathrm{C} 1 \mathrm{G}-2 \mathrm{Gs}$ versus $\mathrm{C} 3 \mathrm{G}-4 \mathrm{Gs}$ was 55/45 \% in December 2012 and 52/48 \% in December 2011.

A second limitation was that this study did not include condoms, $90 \%$ of which are sold in supermarkets, and those data were not available. However, since the overall trend showed only a small decrease of $1 \%$ in contraceptive sales, it can be assumed that the French pill crisis probably had little or no effect on condom sales.

Furthermore, it would have been interesting to include an analysis of the abortion trend between 2012 and 2013. However, French hospital data were not available. We nevertheless conducted a sensitivity analysis incorporating emergency contraceptive sales data into this study. A significant, albeit slight, rise of $4.4 \%$ was reported between 2013 and 2012.

A third limitation was that the number of women exposed to each type of contraceptive could not be clearly determined in this study. More precisely, we could not consider the total number of women who resorted to longterm usage of IUDs, LNG-IUSs and implants (the effects of which generally last for more than 1 year). However, an index was developed, which took the type of contraceptive into account. This index corresponded to the number of months of contraception sold and allowed comparison of sales of contraceptives characterized by regular usage (COCs, NOCCs) with those involving one-time administration (IUDs, OTHCs). This also helped to highlight the overall trend.

Moreover, the use of sales data is essential, since it considers all contraceptives, including those for which the cost is never reimbursed (e.g. C4Gs) and those with minimal reimbursement, such as C3Gs. To strengthen our results, we carried out a sensitivity analysis based on a representative cross-sectional sample of the population covered by the French National Healthcare Insurance Database [24, 25]. This database yielded results similar to our findings, with a $32 \%$ increase in the use of C1G-2Gs in 2013 compared with 2012, and the amount of $20 \mu \mathrm{g}$ C1G-2G use reimbursed in 2013 was 1.9 times greater than that reported in 2012. The corresponding increases observed in our study, based on sales data, were $30 \%$ and 2.1, respectively (see the "Results" section).

A critical element in the management of the French pill crisis concerns NOCCs, including patches and vaginal rings. These contraceptives are similar in composition to C3G-4Gs. This investigation identified a large $45 \%$ decrease in C3G-4G sales but only a moderate $13 \%$ decrease in NOCC sales in 2013 compared with 2012, corresponding to a decrease of only 14,000 women. However, few studies have focused on the risks associated with NOCCs [26, 27]. Supplementary studies would help to clearly evaluate the risks of NOCCs and would allow the French health authorities to compile new guidelines.

Finally, to strengthen their measures concerning C3G4Gs, the ANSM decided to carry out a European reassessment of the benefits and risks associated with these products in order to restrict the indications for $\mathrm{C} 3 \mathrm{G}-4 \mathrm{Gs}$. However, this reassessment did not lead to any change in the marketing authorization for $\mathrm{C} 3 \mathrm{G}-4 \mathrm{Gs}$. These results confirm the importance of a well-structured communication plan, including press conferences to present sales data relating to changes in women's behaviour regarding contraception.

One important outcome of this study focused on IUDs. Very popular in some countries, IUDs were used by fewer than $20 \%$ of French women of childbearing age, despite the fact that this method is widely available and its cost is reimbursed by the national health system [28]. In France, gynaecologists are reluctant to prescribe IUDs for nulliparous women (only $1 \%$ of young women between 15 and 19 years of age use this type of contraceptive). The French pill crisis led to a large increase of $47 \%$ in IUD sales between 2012 and 2013, mostly among women under 40 years of age. More precisely, 61 and $50 \%$ increases in IUD sales were recorded in the 20- to 29-year and 30- to 39-year age groups, respectively. 
These results suggest that the French pill crisis was managed effectively, thanks to a major national communication plan conducted by the French health authorities and real-time monitoring of drug sales. The proportion of C1G-2G/C3G-4G sales was 78/22 \% in December 2013. The distribution of COC sales, classified by oestrogen concentration, changed over the study period (2013 versus 2012). Sales of $20 \mu \mathrm{g} \mathrm{C} 1 \mathrm{G}-2 \mathrm{Gs}$ represented $26 \%$ of COC sales in 2013, compared with $12 \%$ in 2012. Finally, the proportion of women using IUDs and not exposed to hormonal contraceptives increased considerably.

\section{Conclusion}

This study highlights the fact that an effective national communication plan and data on drug sales and reactions from physicians and patients are essential to manage a health crisis and to allow changes in health habits in a society. However, this study was conducted over a short period after the crisis and should be extended over a longer period to confirm this trend reversal regarding contraception. The updated sales data are rather encouraging, as they show that the proportion of $\mathrm{C} 1 \mathrm{G}-2 \mathrm{Gs}$ compared with C3G-4Gs was 79/21\% in April 2014. It would also be interesting to evaluate the impact of the French pill crisis on thromboembolic events, and such a study will be conducted when the relevant hospitalization data are available (at the end of the 2014 year).

Author contribution All authors contributed to the writing of this paper. Specific contributions are as follows: study concept and design: Magali Lemaitre and Mahmoud Zureik; analysis and interpretation of data: Magali Lemaitre, David Syr and Mahmoud Zureik; preparation of the manuscript: Magali Lemaitre, Mahmoud Zureik, Glenn Lastennet, David Syr and Joseph Emmerich.

Conflict of interest disclosure statements David Syr is employed by Celtipharm. Magali Lemaitre, Glenn Lastennet, Joseph Emmerich and Mahmoud Zureik have no potential conflicts of interest.

Financial disclosure This work was supported by funding from the National Agency for the Safety of Medicines and Health Products (ANSM).

Open Access This article is distributed under the terms of the Creative Commons Attribution Noncommercial License which permits any noncommercial use, distribution, and reproduction in any medium, provided the original author(s) and the source are credited.

\section{References}

1. Barritt DW, Jordan SC. Clinical features of pulmonary embolism. Lancet. 1961;1(7180):729-32.

2. Boyce J, Fawcett JW, Noall EW. Coronary thrombosis and conovide. Lancet. 1963;1(7272):111.
3. Effect of different progestagens in low oestrogen oral contraceptives on venous thromboembolic disease. World Health Organization Collaborative Study of Cardiovascular Disease and Steroid Hormone Contraception. Lancet. 1995;346(8990): 1582-8.

4. Jick H, Jick SS, Gurewich V, Myers MW, Vasilakis C. Risk of idiopathic cardiovascular death and nonfatal venous thromboembolism in women using oral contraceptives with differing progestagen components. Lancet. 1995;346(8990):1589-93.

5. Spitzer WO, Lewis MA, Heinemann LA, Thorogood M, MacRae KD. Third generation oral contraceptives and risk of venous thromboembolic disorders: an international case-control study. Transnational Research Group on Oral Contraceptives and the Health of Young Women. BMJ. 1996;312(7023):83-8.

6. Barnett J, Breakwell GM. The social amplification of risk and the hazard sequence: the October 1995 OC pill scare. Health Risk Soc. 2003;5(3):301-13.

7. European Medicines Agency. Position statement: CPMP concludes its assessment of 'third generation' combined oral contraceptives and the risk of venous thromboembolism [document reference: EMEA/CPMP/2250/01/en/Final]. 2001. http://www. ema.europa.eu/docs/en_GB/document_library/Position_statement/ 2009/12/WC500017650.pdf. Accessed 16 Jan 2015.

8. Jick SS, Hernandez RK. Risk of non-fatal venous thromboembolism in women using oral contraceptives containing drospirenone compared with women using oral contraceptives containing levonorgestrel: case-control study using United States claims data. BMJ. 2011;342:d2151.

9. Lidegaard O, Lokkegaard E, Svendsen AL, Agger C. Hormonal contraception and risk of venous thromboembolism: national follow-up study. BMJ. 2009;339:b2890.

10. Lidegaard O, Nielsen LH, Skovlund CW, Skjeldestad FE, Lokkegaard E. Risk of venous thromboembolism from use of oral contraceptives containing different progestogens and oestrogen doses: Danish cohort study, 2001-9. BMJ. 2011;343:d6423.

11. Austin H, Lally C, Benson JM, Whitsett C, Hooper WC, Key NS. Hormonal contraception, sickle cell trait, and risk for venous thromboembolism among African American women. Am J Obstet Gynecol. 2009;200(6):620 e1-3.

12. Parkin L, Sharples K, Hernandez RK, Jick SS. Risk of venous thromboembolism in users of oral contraceptives containing drospirenone or levonorgestrel: nested case-control study based on UK General Practice Research Database. BMJ. 2011;342: d2139.

13. European Medicines Agency. Pharmacovigilance Working Party (PhVWP): May 2011 plenary meeting [document reference: EMA/CHMP/PhVWP/394737/2011]. 2011. http://www.ema. europa.eu/docs/en_GB/document_library/Report/2011/05/WC50 0106708.pdf. Accessed 16 Jan 2015.

14. Haute Autorité de Santé. Contraceptifs oraux estroprogestatifs: préférez les «pilules» de 1re ou 2e génération-fiche BUM. 2012. http://www.has-sante.fr/portail/jcms/r_1439689/fr/ contraceptifs-oraux-estroprogestatifs-preferez-les-pilules-de-1reou-2e-generation-fiche-bum. Accessed 16 Jan 2015.

15. Agence Nationale d'Accréditation et d'Évaluation en Santé. Recommandations pour la pratique clinique. Stratégies de choix des méthodes contraceptives chez la femme: recommandations. 2004. http://www.choisirsacontraception.fr/pdf/contraception recommandations_has.pdf. Accessed 16 Jan 2015.

16. Haute Autorité de Santé. Réévaluation des contraceptifs oraux de troisième génération (annexe commune)_juin 2012. 2012. http:// www.has-sante.fr/portail/jcms/c_1322400/fr/reevaluation-descontraceptifs-oraux-de-troisieme-generation-annexe-communejuin-2012. Accessed 16 Jan 2015.

17. Tricotel A, Raguideau F, Collin C, Zureik M. Estimate of venous thromboembolism and related-deaths attributable to the use of 
combined oral contraceptives in France. PLoS One. 2014;9(4): e93792.

18. Celtipharm. Secondary real-time health data for sustainable care. http://www.xpr-so.com/pages/Public/Accueil.aspx. Accessed March 2014.

19. Kish J. Survey sampling. New York: Wiley; 1965.

20. Pivette M, Mueller JE, Crepey P, Bar-Hen A. Surveillance of gastrointestinal disease in France using drug sales data. Epidemics. 2014;8:1-8.

21. Crepey P, Pivette M, Bar-Hen A. Quantitative assessment of preventive behaviors in France during the Fukushima nuclear crisis. PLoS One. 2013;8(3):e58385.

22. Pivette M, Mueller JE, Crepey P, Bar-Hen A. Drug sales data analysis for outbreak detection of infectious diseases: a systematic literature review. BMC Infect Dis. 2014;14(1):604.

23. Lidegaard O, Nielsen LH, Skovlund CW, Lokkegaard E. Venous thrombosis in users of non-oral hormonal contraception: followup study, Denmark 2001-10. BMJ. 2012;344:e2990.
24. Blin P, Lassalle R, Dureau-Pournin C, et al. Insulin glargine and risk of cancer: a cohort study in the French National Healthcare Insurance Database. Diabetologia. 2012;55(3):644-53.

25. Bongue B, Laroche ML, Gutton S, et al. Potentially inappropriate drug prescription in the elderly in France: a population-based study from the French National Insurance Healthcare system. Eur J Clin Pharmacol. 2011;67(12):1291-9.

26. Sidney S, Cheetham TC, Connell FA, et al. Recent combined hormonal contraceptives (CHCs) and the risk of thromboembolism and other cardiovascular events in new users. Contraception. 2013;87(1):93-100.

27. Dinger J, Mohner S, Heinemann K. Cardiovascular risk associated with the use of an etonogestrel-containing vaginal ring. Obstet Gynecol. 2013;122(4):800-8.

28. Moreau C, Bohet A, Hassoun D, Teboul M, Bajos N. Trends and determinants of use of long-acting reversible contraception use among young women in France: results from three national surveys conducted between 2000 and 2010. Fertil Steril. 2013;100(2):451-8. 